\title{
Evaluation of G6G Synchronization Protocol in the Treatment of Postpartum Anestrous Ongole Cows
}

\author{
K. Sahithi*, K. Sadasiva Rao, M. Srinivas and N. Lakshmi Rani \\ Department of Veterinary Gynaecology and Obstetrics, \\ NTR College of Veterinary Science, Gannavaram, \\ Sri Venkateswara Veterinary University, Andhra Pradesh, India. \\ *Corresponding author
}

\begin{tabular}{|l|}
\hline Ke y w or d s \\
Anestrous, Estrus, \\
G6G, Ongole cows, \\
Postpartum
\end{tabular}

A B S T R A C T
Treatment of postpartum lactating anestrous Ongole cows $(n=8)$ using G6G hormonal protocol was undertaken. Following the treatment, 7 cows exhibited estrus after second $\mathrm{PGF}_{2} \alpha$ injection. The estrus detection rate was $87.5(7 / 8)$ per cent. Mean time to onset of estrus was observed as $34.3 \pm 4.08 \mathrm{~h}$. The per cent of cows that showed intense, intermediate and weak estrus were 42.86 , 57.14 and 0.0 per cent. The peak estrus synchrony with highest number of animals exhibiting estrus between 24 to $48 \mathrm{~h}$ was 57.14 (4/7) per cent. The artificial insemination submission rate was 87.5 (7/8) per cent. The conception rate at induced estrus in the present study for G6G treatment group was 62.5 (5/8) per cent. In the present study, overall conception rate among the postpartum lactating anestrous Ongole cows was higher with $75.0(6 / 8)$ per cent in G6G group compared to 25.0 (2/8) per cent in the control group. The results of the present study with inseminations at induced estrus in postpartum lactating anestrous Ongole cows appears to be an effective method of managing fertility by using G6G protocol.

\section{Introduction}

India is a treasure house of Bos indicus breeds. Ongole was the first Indian breed of cattle to gain worldwide recognition for its adaptability to various climatic conditions (Vinoo et al., 2007). Clinical surveys in India have revealed that the incidence of postpartum anestrum due to inactive ovaries affects the economy of farming community. It is one of the most common reproductive disorders encountered in livestock farms leading to prolonged intercalving period and reduced milk production. Estrus synchronization protocols were one of the effective methods to induce estrus and ovulation with enhanced conception rates in anestrous cows. Use of $\mathrm{G} 6 \mathrm{G}$ protocol in treatment of postpartum anestrous cows was 
studied by several scientists (Heidari et al., 2017). The present study was undertaken to evaluate the efficacy of G6G protocol on pattern of estrus and fertility in postpartum lactating anestrous Ongole cows.

\section{Materials and Methods}

Postpartum anestrous Ongole cows maintained under standard feeding and manage mental conditions at Cattle Project, Livestock Research Station, Lam Farm, Guntur, were included in this study. These postpartum anestrous cows were randomly allotted into two experimental groups (G6G and Control groups each consisting of 8 animals). In G6G group, cows were administered with IM injection of Cloprostenol sodium (Pragma, Intas) @ $500 \mu \mathrm{g}$ on day 0 , followed by IM injection of GnRH analogue (Buserelin acetate, Pregulate, Virbac) @ $10 \mu \mathrm{g}$ on day 2 and Ovsynch treatment was initiated with a gap of 6 days which consisted of an IM injection of GnRH analogue (Buserelin acetate, Pregulate, Virbac) @ $10 \mu \mathrm{g}$ on day 8, IM injection of Cloprostenol sodium (Pragma, Intas) @ $500 \mu \mathrm{g}$ on day 15 and another dose of GnRH analogue (Buserelin acetate, Pregulate, Virbac) @ $10 \mu \mathrm{g}$ on day 17 and timed A.I (TAI) was done at 16-18 hr after the final dose of GnRH injection whereas, 8 untreated cows were kept as Control group. At induced/spontaneous estrus the following parameters were studied viz., estrus response, intensity of estrus and degree of estrus synchrony. In G6G group, fixed time inseminations were performed at 16-18 hrs after the final dose of GnRH injection, while in control group the cows were inseminated at spontaneous estrus by adopting AM-PM rule. Cows in estrus were inseminated using good quality of frozen thawed semen. Cows detected at subsequent estrus were reinseminated up to 3 cycles and in non return cases pregnancy was confirmed per rectum at 60 days after AI. Conception rate and overall conception rate were recorded for both the groups under study. The results were analyzed as per standard statistical procedures.

\section{Results and Discussion}

The estrus response percentage following G6G protocol was 87.5 (7/8), while in control group it was 37.5 (3/8). Three cows in G6G protocol exhibited estrus after first $\mathrm{PGF}_{2} \alpha$ injection during the treatment period. This could be due to presence of corpus luteum at the time of $1^{\text {st }} \mathrm{PGF}_{2} \alpha$ in this group. During this period, none of the cows exhibited visible estrus signs in control group. On the contrary, Ahmed et al., (2017) recorded 100.00 per cent estrus response with G6G protocol. The variation in the estrus response could be attributed to season, parity, type of feeding, management practices and geographical variations.

The mean time to onset of estrus was $34.3 \pm 4.08$ (24 to 48 ) hours in G6G group. Ahmed et al., (2017) reported that the onset of estrus was $46.40 \pm 0.33 \mathrm{~h}$, which was longer than the present observation.

The intensity of estrus in G6G group was intense, intermediate and weak in 42.86, 57.14 and 0.0 per cent of cows, respectively with peak synchrony of 57.14 (4/7) per cent in cows in estrus between 24 to 48 hours after treatment. The present findings are in contrast to Ahmed et al., (2017) who reported intense estrus $(28.57 \%)$, intermediate estrus $(57.14 \%)$ and weak estrus (14.28\%) with G6G treatment. All the three (3/10) cows in the control group of the present study have shown intermediate to weak estrus during the treatment period.

In the present investigation, intense estrus was observed at the rate of 42.86 per cent (3/7) in G6G group, out of which all have conceived (3/3). Intermediate estrus was observed at the 
rate of 57.14 per cent (4/7) in G6G, out of which two cows conceived (2/4). In the control group, one out of two cows that exhibited intermediate estrus was conceived, where as the single cow that exhibited weak estrus failed to conceive in the present study.

The conception rates were 62.5 (5/8) and 12.5 (1/8) per cent in G6G group and control groups, respectively. This was similar to the findings of Ahmed et al., (2017) who reported conception rate of 71.4 per cent. The overall conception rate in postpartum lactating anestrous Ongole cows treated with G6G group was $75.0(6 / 8)$ per cent, while in control group, the same was $25.0(2 / 8)$ per cent. On the contrary, the overall conception rate in G6G protocol group recorded by Dirandeh et al., (2015) was 50.00 per cent, which was lower than the present study. The variations in the conception rate might be due to differences in active principle of the hormones, type of breed and seasonal variations.

It was concluded from the present study that G6G protocol could be effectively used to resume ovarian cyclicity in postpartum anestrous cows under field conditions by practicing veterinarians.

\section{Acknowledgements}

The authors thank Scientists of Livestock Research Station, Lam Farm, Guntur and Sri
Venkateswara Veterinary University (SVVU), Tirupati, for extending the financial support to conduct the research.

\section{References}

Ahmed N, Doley S H and Vanlalhriatpuia 2017 Inclusion of ovulation synchronization strategies for augmentation of fertility in postpartum anestrus crossbred cows. International journal of chemical studies $5: 25-26$.

Dirandeh E, Roodbari A R, Gholizadeh M, Deldar H, Masoumi R, Kazemifard M and Colazo M G 2015 Administration of prostaglandin $\mathrm{F} 2 \alpha 14 \mathrm{~d}$ before initiating a G6G or a G7G timed artificial insemination protocol increased circulating progesterone prior to artificial insemination and reduced pregnancy loss in multiparous Holstein cows. Journal of Dairy Science 98 : 5414-5421.

Heidari F, Dirandeh E, Pirsaraei Z A and Colazo M G 2017 Modifications of the G6G timed-AI protocol improved pregnancy per AI and reduced pregnancy loss in lactating dairy cows. Animal 11 : 2002-2009.

Vinoo R, Rao G N, Gupta B R and Rao K B 2007 A study on coat colour in ongole calves. Indian Journal of Animal Research $41: 77-78$.

\section{How to cite this article:}

Sahithi, K., K. Sadasiva Rao, M. Srinivas and Lakshmi Rani, N. 2019. Evaluation of G6G Synchronization Protocol in the Treatment of Postpartum Anestrous Ongole Cows. Int.J.Curr.Microbiol.App.Sci. 8(09): 2349-2351. doi: https://doi.org/10.20546/ijcmas.2019.809.270 